\title{
Hydrothermal Conversion of Lipid-Extracted Microalgae Hydrolysate in the Presence of Isopropanol and Steel Furnace Residues
}

\author{
Jonathan L. Wagner ${ }^{1} \cdot$ Julio Perin $^{2} \cdot$ Renato Sano Coelho $^{3} \cdot$ Valeska P. Ting ${ }^{4}$. \\ Christopher J. Chuck ${ }^{5}$ Telma Teixeira Franco ${ }^{2,3}$
}

Received: 11 December 2016 / Accepted: 17 April 2017 / Published online: 20 May 2017

(c) The Author(s) 2017. This article is an open access publication

\begin{abstract}
Purpose Microalgae have a high potential as a feedstock for the production of biofuels, either indirectly, through the extraction of lipids, which can be transformed into biodiesel, or directly via whole cell conversion using hydrothermal liquefaction (HTL). Both approaches have disadvantages, due to the high cost of cultivating microalgae with sufficient lipid content $(>40 \%)$, while the whole cell conversion produces low quality oils, which require significant further upgrading. This work investigated the possibility of realising the benefits of both processes, by studying the liquefaction reaction of a lipid-extracted algae hydrolysate.
\end{abstract}

Electronic supplementary material The online version of this article (doi:10.1007/s12649-017-9944-7) contains supplementary material, which is available to authorized users.

Christopher J. Chuck

c.chuck@bath.ac.uk

Telma Teixeira Franco

franco@feq.unicamp.br

1 Centre for Doctoral Training in Sustainable Chemical Technologies, Department of Chemical Engineering, University of Bath, Claverton Down, Bath BA2 7AY, UK

2 Nucleo Interdisciplinar de Planejamento Energético - NIPE, UNICAMP Cidade Univesitaria Zeferino Vaz, Cora Coralina 330, Campinas, SP 13083-896, Brazil

3 Faculdade de Engenharia Química, UNICAMP Cidade Universitária Zeferino Vaz, Av. Albert Einstein, 500, Campinas, SP 13083-852, Brazil

4 Department of Mechanical Engineering, University of Bristol, Bristol BS8 1TR, UK

5 Department of Chemical Engineering, University of Bath, Claverton Down, Bath BA2 7AY, UK
Methods In order to enhance oil yields, the reaction was conducted in the presence of varying loadings of iso-propyl alcohol (IPA) and applied two waste steel furnace residues as potential liquefaction catalysts.

Results Primarily, The lipid extraction process needs to be optimized to reduce the amount of acid contaminant within the liquefaction medium. For the HTL process, the addition of $50 \mathrm{vol} \%$ IPA resulted in remarkably high oil yields of up to $60.2 \mathrm{wt} \%$ on an organic basis, whereas the two furnace residues had no positive effect on the product distribution, and instead favoured the formation of solid reaction products. Nevertheless, the results suggested that the presence of iron potentially reduced the nitrogen and oxygen content of the bio-oil.

Conclusions As such, HTL is a suitable method for valorising lipid-extracted algal biomass, where the bio-oil yields can be enhanced substantially by using IPA in conjunction with the water.

Keywords Hydrothermal liquefaction · Biofuel · Microalgae $\cdot$ Heterotrophic $\cdot$ Biorefinery

\section{Introduction}

Microalgae have long been seen as a highly promising feedstock for the production of bio-fuels. They display much higher solar to biomass efficiencies than land-based plants [1], they do not directly compete with food production and can provide secondary functions such as wastewater treatment, carbon sequestration or the expression of valuable by-products, which may help to subsidise the overall fuel production process [2].

Historically, most research has focused on the extraction of algal lipid, and the subsequent transesterification 
into biodiesel $[3,4]$. Although this technology is relatively well established, it has been estimated that it requires algae with a lipid content of at least $40 \%$ at a biomass cost of no more than $\$ 0.25 \mathrm{~kg}^{-1}$ to be economically viable [1]. As the expression of algal lipids carries a much higher metabolic cost than proteins or carbohydrates [5], growth rates of lipid-rich algae are significantly reduced, eliminating one of the major advantages of using algae in the first place. Furthermore, the cultivation of pure, lipid-producing algae species requires carefully controlled growth conditions, resulting in significant increases to the cultivation costs [6].

A promising alternative to lipid-based processes is hydrothermal liquefaction (HTL), where the algae are reacted in liquid water close to its critical point. This process forms a crude bio-oil, which can be ultimately processed into conventional transportation fuels. As HTL converts the entire algae, not just lipids, it can utilise much cheaper and faster growing algae. In addition, it may facilitate the recovery of nutrients, such as nitrogen and phosphorus, to the aqueous phase, facilitating recycling for further algae growth, or allowing it to be used as a liquidbased fertilizer. However, the bio-oil has a much lower quality than lipids, containing high concentrations of oxygen and nitrogen, and poor flow properties. Consequently, significant further upgrading is required before the oil can be fractionated into fuels.

A potential way of realising the benefits from both processes could be the combination of algal lipid production with subsequent HTL of the remaining biomass components. In this way, the production of the lower value HTL oil could help to offset the production costs for the higher value lipids, and may allow the use of faster growing algae with lower lipid content, compared to a solely lipid-based process.

The lipid-extracted algae would be expected to consist predominantly of protein and carbohydrate derived material, which tend to yield significantly lower HTL yields than lipids [7, 8]. Consequently, it may be desirable to conduct the HTL of this algae residue in the presence of polar organic solvents, such as ethanol, acetone, or ethylene glycol, or organic waste products, such as glycerol, which have been previously found to enhance bio-oil yields, compared to water-only reactions [9-12]. These enhancements have been generally associated with reduced critical temperatures and pressures allowing the use of milder reaction conditions and lower dielectric constants, helping to dissolve high-molecular-weight products [13]. It has also been suggested that the hydrogen donation abilities of certain solvents such as ethanol could help to improve the quality of the final bio-oil [14].

One of the most comprehensive studies employed eleven different solvents (water, ethylene glycol, methanol, ethanol, n-propanol, isopropanol, acetone, ethyl acetate, 1,4-dioxane, tetraline and benzene) for the conversion of Chlorella pyrenoidosa at $350^{\circ} \mathrm{C}$ [9].

The highest bio-oil yields, ranging from 51.4 to $57.0 \%$ were obtained in the highly polar solvents ethylene glycol, ethanol, acetone and ethyl acetate, significantly exceeding the yields obtained in water (43\%). Further optimization of the reaction conducted in ethanol produced a bio-oil yield of $65.1 \%$, however the overall product recovery exceeded the organic content of the algae, indicating consumption of the reaction solvent. Similar findings were made during the conversion of Chlorella pyrenoidosa in acetone, which achieved remarkable bio-oil yields of $78.9 \%$ at $290^{\circ} \mathrm{C}$, but with an overall product recovery of $106.9 \%$ [10]. In addition, contrary to water liquefaction, the resulting oil contained a higher nitrogen content than algae.

HTL in pure solvent also requires complete biomass drying, incurring significant energy penalties, and results in low critical temperatures, restricting the maximum allowable reaction temperature. For these reasons, HTL in pure solvent may be undesirable. Instead, the liquefaction could be conducted in solvent-water mixtures, which were often found to produce higher yields than the reactions in the pure solvent $[10,12,13,15]$. In these studies, the optimal solvent-water ratios were found to be strongly dependent on both the solvent, and the selected reaction temperature, and it was suggested that the optimal solvent concentration is governed by the proximity of the critical temperature of the mixture to the reaction temperature [13]. However, for polar solvents, the subsequent recovery of the bio-oil and reaction solvent may be more challenging, compared to conventional HTL reactions, due to the high miscibility of the solvent with the aqueous phase. Furthermore, only few solvent-water combinations have been studied to date, and to the best of our knowledge have not yet been applied to the conversion of lipid-extracted algal residue. One of the solvents that appears relatively neglected for these reactions so far is isopropanol (IPA), despite its known ability to act as a hydrogen donor for transfer hydrogenation reactions, $[16,17]$ potentially helping to improve the quality of the resulting bio-oil, and consequently has been selected for this study.

Another method of enhancing bio-oil yields is the addition of catalysts. Liquefaction yields from the conversion of carbohydrates were found to be positively influenced by the addition of the base catalyst sodium carbonate $\left(\mathrm{Na}_{2} \mathrm{CO}_{3}\right)$ [7], whereas the noble metal catalysts $\mathrm{Pd} / \mathrm{C}$ and $\mathrm{Pt} / \mathrm{C}$ were found to produce significantly enhanced bio-oil yields with improved flow properties and a reduced nitrogen content $[18,19]$. Despite this, due to their high cost, the application of noble metal catalysts for large-scale HTL of algae is unlikely to represent an economically feasible solution. Therefore, alternative, low-cost materials need to be identified that can be added to the liquefaction medium instead. 
There is some evidence that lower cost materials, such as $\mathrm{FeSO}_{4}$ [20], or $\mathrm{Fe}_{3} \mathrm{O}_{4}$ can work to enhance bio-oil yields [21]. One source of inexpensive material is furnace residues or furnace slag. This material is a mix of $\mathrm{Fe}, \mathrm{Ca}, \mathrm{Mg}$, $\mathrm{Al}$ and $\mathrm{Si}$ oxides, that can be added to a reactions to impart a low cost catalytic effect while not being valuable enough to need to be recovered and purified. These materials have been demonstrated to impart a positive effect on processes such as gasification [22], catalytic cracking of triglycerides [23], hydrogen production [24] or degradation of dye molecules in water [25].

In this investigation, the possibility of combining HTL with algal lipid production was evaluated by upgrading an algal cake, recovered from a lipid-extracted algae hydrolysate solution, using the HTL process. The reactions were conducted both in pure water, and in the presence of varying concentrations of isopropanol (IPA), in an attempt to enhance the overall bio-oil yields. In addition, the effect of adding two steel furnace residues on the product distribution obtained from the conversion of the algae cake was evaluated.

\section{Methodology}

\section{Materials}

Ladle-furnace-residue (LFR) and electric-arc furnace slag (EAFS), were obtained from ArcelorMittal's iron smelter in Piracicaba, SP, Brazil. All lab solvents and chemicals were obtained from commercial sources, and were all laboratory grade $(99 \%+$ purity), specifically these were chloroform (Synth), heptane (Sigma-Aldrich) and IPA (Sigma-Aldrich).

\section{Biomass Preparation}

\section{Algae Cultivation and Lipid Extraction}

Lipid-rich algae (Chlorella sp. strain, obtained from the Canadian Phycological Culture Centre) was produced under continuous flow, at a biomass concentration of $30 \mathrm{~g} \mathrm{~L}^{-1}$, applying heterotrophic conditions, using glucose as the carbon source, as described elsewhere [26].

Solvent extraction of algal lipids is reviewed fully elsewhere [27]. In this investigation, prior to lipid extraction, the algae slurry was mixed with $0.1 \mathrm{~g} \mathrm{H}_{2} \mathrm{SO}_{4}$ for each gram of dry cell weight (dcw) and hydrolysed in a PHOENIX AV100 Plus autoclave at $120^{\circ} \mathrm{C}$ for $1 \mathrm{~h}$. Subsequently, the lipids were extracted using a 1:4 mixture of ethanol and hexane at a ratio of $2.5 \mathrm{~mL} \mathrm{~g}^{-1}(\mathrm{dcw})$. The solvent/algae mixture was stirred for $1 \mathrm{~min}$ and allowed to rest until spontaneous phase separation occurred, followed by the recovery of the top phase containing hexane and lipids. This procedure was repeated four more times (using hexane only) and the recovered hexane-lipid phase was separated by evaporation under vacuum.

\section{Hydrolysate Work-Up}

Following lipid-extraction, the algal hydrolysate was centrifuged to remove any residual hexane and to reduce the water volume by $43 \%$. Subsequently, the remaining biomass was neutralized using a $5 \mathrm{M}$ sodium hydroxide solution, followed by a second centrifugation step to obtain a wet paste with a water content of $72 \mathrm{wt} \%$. Finally, the cake was oven-dried at $70^{\circ} \mathrm{C}$, and finely ground prior to the HTL reaction.

\section{Hydrothermal Reactions}

\section{Reactor Set-Up}

Hydrothermal conversion reactions of the dry algal cake were conducted in a $100 \mathrm{~mL}$ Parr reactor (series $4560 \mathrm{mini}$ reactor system). Each reaction converted $5 \mathrm{~g}$ of biomass, in the presence of a total of $50 \mathrm{~mL}$ of reaction solvents, consisting of varying concentrations of deionized water and/ or IPA. Catalytic reactions employed an additional $5 \mathrm{~g}$ of finely ground material, either LFR or EAFS.

Prior to reaction, the reactor was carefully sealed and charged with 10 bar nitrogen to reduce the vaporisation of the reaction solvent. Reactions were stirred at $180 \mathrm{rpm}$, and allowed to proceed for $1 \mathrm{~h}$, once the desired reaction temperature $\left(220\right.$ or $\left.310^{\circ} \mathrm{C}\right)$ had been reached. Reactor pressures ranged from 22 bar for reactions at $220^{\circ} \mathrm{C}$ in pure water to $132 \mathrm{bar}$ at $310^{\circ} \mathrm{C}$ and an IPA loading of $50 \mathrm{vol} \%$. Following reaction, the heating mantle was removed and the reactor was allowed to cool down to room temperature $\left(<40^{\circ} \mathrm{C}\right)$. Heating times ranged from 56 to $71 \mathrm{~min}$, whereas reactor cooling required between 90 and 120 min, giving a total contact time between reagents and catalysts of up to $4 \mathrm{~h}$.

\section{Product Recovery}

Following the reaction, the gases were vented, the reactor was opened and the reaction products were vacuum filtered through pre-weighed filter paper. This allowed the recovery of the aqueous product phase. A small aliquot of this phase was oven-dried overnight at $70^{\circ} \mathrm{C}$ to determine the yield of the water phase residue. Subsequently, the reactor and filter paper residue were washed with chloroform, until the solvent remained clear.

In order to extract IPA and water-soluble organics from the water phase, the aqueous and solvent phases were 
recombined and thoroughly mixed prior to gravity separation. To determine the impact of this additional processing step, baseline reactions were conducted at $310^{\circ} \mathrm{C}$ with IPA loadings of 0 and $50 \%(\mathrm{v} / \mathrm{v})$, without recombination of the aqueous and solvent phases.

Following recovery of the oil phase, the solvent was removed at $60^{\circ} \mathrm{C}$ and under vacuum $(120$ mbar $)$, before further separating the bio-oil product into a heptane soluble (light-oil) and chloroform soluble (heavy-oil) fraction. The filter paper was dried at $70^{\circ} \mathrm{C}$ overnight, before determining the solid product weight. For reactions involving catalysts, the catalyst weight was subtracted before calculating the solid yield.

\section{Product Analysis}

\section{Algae Analysis}

CHNS analysis of the algae cake was carried out on a vario MACRO cube analyser, Elementar (Hanau, Germany), with a combustion tube temperature of $1150^{\circ} \mathrm{C}$ and a reduction tube temperature of $850^{\circ} \mathrm{C}$.

Thermogravimetric analysis (TGA) of the press cake was carried out by on a TGA/DSC1 analyser by METTLER (Zürich, Switzerland), using a ramp rate of $10^{\circ} \mathrm{C} \mathrm{min}^{-1}$ to a maximum temperature of $700^{\circ} \mathrm{C}$.

The total organic carbon (TOC) and total nitrogen (TN) contents in the 'acid water' and 'neutral' water were analysed using a Shimadzu TOC/TN analyzer, at dilutions of $2 \mathrm{vol} \%$.

The glucose content in the 'acid water' and 'neutral water' phase was determined using a commercial enzymatic glucose-oxidase assay kit by Bioliquid® using tenfold dilution.

HTL Reaction Products In addition to the CHNS analysis, the composition of the solid reaction products was also determined using SEM-EDX analysis. Prior to analysis, the samples were gold coated using a MITECH Sputter Coater, Model K450 (Kent, United Kingdom). The samples were then analysed using an LEO Electron Microscope (Cambridge, UK), model number Leo 440i using a 6070 EDX detector. The accelerating potential was $20 \mathrm{kV}$ with a beam current of 600 pA. Elemental composition was determined from an average of 10 different area scans.

To evaluate the degree of catalyst leaching into the aqueous and bio-oil phases, the 'elemental retention' of catalytic material in the solid phase was calculated using following formula:

$\mathrm{X}_{\mathrm{P}, \mathrm{I}} \times \mathrm{m}_{\mathrm{P}} /\left(\mathrm{X}_{\mathrm{C}, \mathrm{I}} \times \mathrm{m}_{\mathrm{C}}+\mathrm{X}_{\mathrm{A}, \mathrm{I}} \times \mathrm{m}_{\mathrm{A}}\right)$.

where $X_{i}$ Elemental content of elemental $i$ and $m$ mass. Subscripts P, C and A stand for product, catalyst and algae, respectively.
Error Analysis The reactions conducted in pure water were carried out in duplicate, and are represented as averages, together with their standard deviation. Whilst the catalytic reactions are based on single-data points, the error is based on the maximum deviation obtained from the wateronly reactions. Errors for the elemental retention of catalytic materials to the solid phase are based on the standard deviation of the ten separate area scans, during the SEM-EDX analysis.

\section{Results and Discussion}

\section{Biomass Preparation}

The overall process flow diagram for producing fuels and products from algal biomass is given in Fig. 1. The lipid extraction process employed harsh hydrolysis conditions, using $0.1 \mathrm{~g} \mathrm{H}_{2} \mathrm{SO}_{4}$ per gram of biomass, to help break up the biomass. Because of this, significant work-up was required to neutralize the lipid-extracted algae hydrolysate before the algae residue could be applied to the HTL reaction.

First, the hydrolysate was centrifuged to remove any residual hexane and reduce the water volume by $43 \%$.

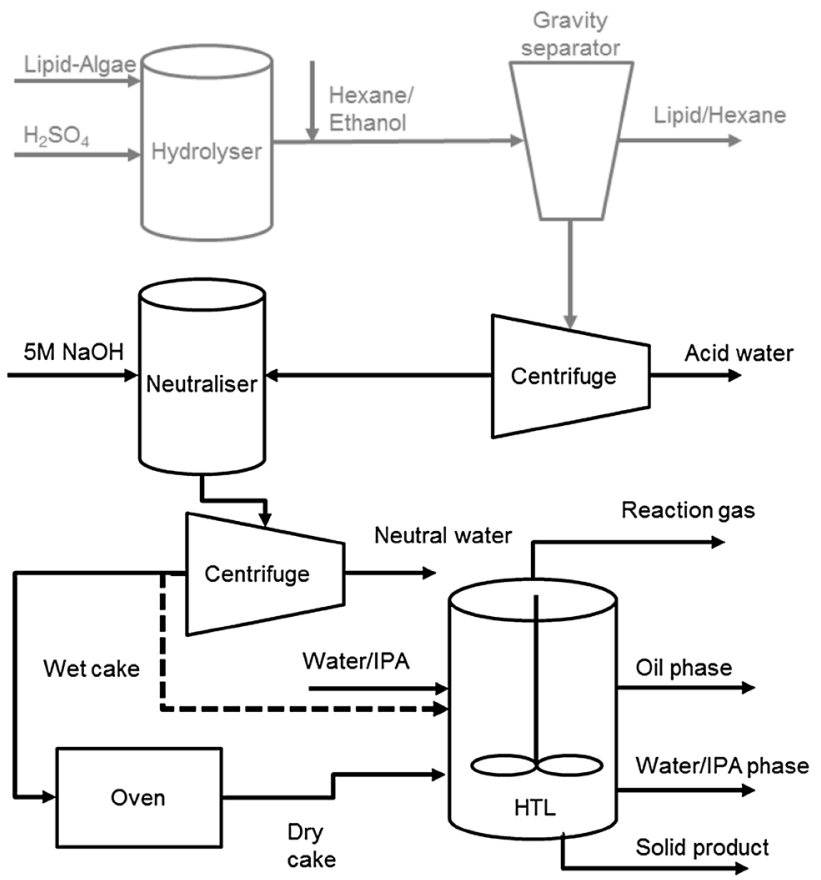

Fig. 1 Schematic demonstrating the production of lipid and HTL bio-oil from one algal source. The grey lines indicate the lipid extraction stages, the black the HTL processing. The dashed line indicates that in an industrial process there would be no need for drying the wet cake 
Subsequently, the acid slurry was neutralized using a $5 \mathrm{M} \mathrm{NaOH}$ solution, followed by a second centrifugation step to recover a wet biomass cake, containing a residual water content of $72 \%$. Finally, to facilitate lab-scale processing, this cake was dried at $70^{\circ} \mathrm{C}$ and finely ground prior to the HTL reactions. However, this step was solely conducted to facilitate the accurate determination of the algae reaction weight and allow algae analysis in our study, and would not be required in an industrial set-up.

The resulting algae cake contained a remarkably high ash content of $52.9 \%$, which could be partially attributed to the high amounts of sulphuric acid and sodium hydroxide used in the lipid extraction and algae cake recovery process. Based on the quantity of sodium hydroxide added to neutralize the hydrolysate solution, sodium sulphate $\left(\mathrm{Na}_{2} \mathrm{SO}_{4}\right)$ was estimated to account for $33.0 \%$ of the total algae cake weight, or $62.4 \%$ of its ash and $85.6 \%$ of its sulphur content. The remaining ash content could be attributed to micronutrients, including calcium chloride, magnesium sulphate and potassium phosphates, as well as oxidation products from the reaction of sulphuric acid with the algae itself, such as ammonium sulphate, and carbonates produced during the cultivation of the algae.

Whilst the dewatering and neutralization of the hydrolysed algae residue was necessary to produce a suitable HTL feedstock, it also resulted in a significant loss of organic biomass components. Using the results from the total carbon and nitrogen analysis of the water phase, it was possible to calculate the elemental distribution to the dry cake and the two recovered water phases (Table 1). This analysis shows that only $44 \%$ of carbon and $39 \%$ of nitrogen from the lipid-extracted hydrolysate were recovered into the dry cake, whereas the remainder was lost during the two centrifugation steps. $11.6 \%$ of the carbon content in the neutral water and $14.6 \%$ of the carbon content in the acid water could be directly attributed to glucose, one of the main products from the hydrolysis of carbohydrates. Therefore, this sugar accounted for $7.5 \%$ of the total carbon in the hydrolysate and could potentially be recycled back for further algae cultivation.

The sulphur phase was predominantly associated with the sulphuric acid present in the hydrolysate. Even though a large amount of sulphur was lost during the two

Table 1 Elemental distribution of hydrolysed algal residue to the dry cake, neutral water and acid water phases, after work-up process

\begin{tabular}{llll}
\hline & Carbon $(\%)$ & Nitrogen $(\%)$ & Sulphur $(\%)$ \\
\hline Dry cake & 43.6 & 39.1 & 24.5 \\
Neutral water & 24.1 & 24.5 & 32.1 \\
Acid water & 32.3 & 36.4 & 43.5 \\
\hline
\end{tabular}

centrifugation steps, just under a quarter $(24.5 \%)$ of the total sulphur was retained within the dry algae cake.

\section{HTL in the Presence of IPA}

\section{Optimization of Product Recovery Method}

Prior to investigating the detailed relationship between IPA loadings and bio-oil yields, the effect of the product recovery method was investigated at $310^{\circ} \mathrm{C}$ (Fig. 2). The results show that the bio-oil yields were significantly enhanced when the aqueous phase was extracted with chloroform. For HTL in pure water, the bio-oil yields more than doubled from 6.6 to $13.4 \mathrm{wt} \%$, predominantly associated with an increase in the light, heptane-soluble oil fraction. An even bigger effect was observed for the reaction conducted in the presence of $50 \mathrm{vol} \%$ IPA. Without water extraction, the total bio-oil yields amounted to only $2.4 \mathrm{wt} \%$, but increased to $28.3 \mathrm{wt} \%$ after the aqueous phase was washed with chloroform, a more than 10 -fold increase.

The differences between the water-only and the 50 vol\% IPA reaction can be associated with the high polarity of IPA, causing it to partition to the water phase, together with dissolved bio-oil components. Even in the absence of IPA, the difference in bio-oil recovery with and without chloroform washing of the water phase was significantly higher than the 20 or $30 \%$ previously reported in the literature [28]. This could be related to the complete absence of lipid-derived products from the algae cake used for this study, and a higher proportion of smaller, more polar organics, produced from the carbohydrate and protein fractions.

Whilst for conventional HTL there is currently no consensus whether the increase in bio-oil yields justifies the

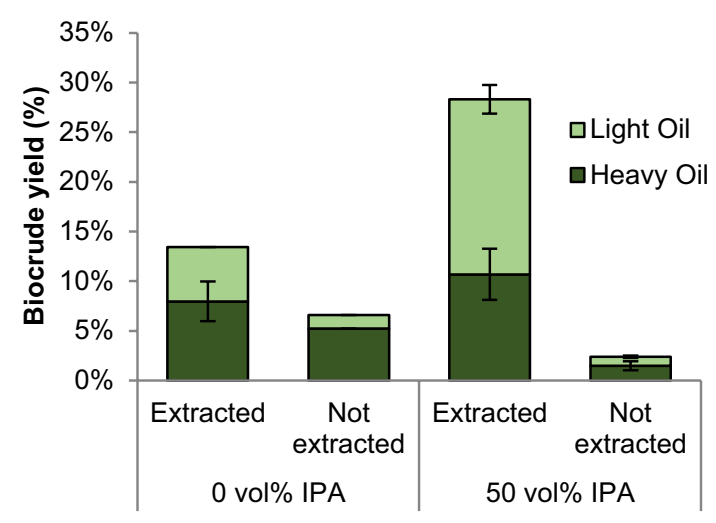

Fig. 2 Effect on the bio-oil yields of extracting the aqueous phase with chloroform for 0 and $50 \%$ IPA/water fractions (reaction at $\left.310^{\circ} \mathrm{C}\right)$ 
additional costs of the solvent extraction procedure [29], it is clear that the HTL of the algae cake in the presence of IPA appears to be only feasible if the water phase is subsequently extracted to recover IPA and the organic reaction products. Consequently, this approach was applied to all subsequent experiments.

While washing with a lipophilic solvent such as $\mathrm{CHCl}_{3}$ allows extensive recovery of the bio-oil fraction, it is unclear whether this would be feasible on an industrial scale. Similar biofuel production processes recycle the finished fuel as a solvent, or use fossil fuels to increase the yield of the final product [4]. Undoubtedly, whatever solvent is used to increase bio-oil yields from the water phase would need to be recycled efficiently, with the IPA, in an industrial process.

\section{Effect of IPA Concentration on Product Distribution}

In this study, the maximum IPA loading in the reactor was limited to $50 \mathrm{vol} \%$. Firstly, $50 \mathrm{vol} \%$ was seen to be the maximum feasible concentration that could be employed industrially, without requiring excessive biomass drying, and losing one of the major advantages of the HTL process. Secondly, the applied reaction temperature of $310^{\circ} \mathrm{C}$ corresponds to the critical temperature of a 40 vol\% IPA-water solution, as predicted using the Peng-Robinson equation of state within Aspen Hysys ${ }^{\circledR}$. Operating at 50 vol\% IPA therefore ensured that the maximum possible IPA concentration in the liquid phase was achieved, without causing excessive evaporation of IPA, resulting in operation above the design pressure of the reactor. Finally, results from previous HTL studies conducted in water-solvent mixtures suggested that maximum bio-oil yields were obtained when the critical temperature of the mixture corresponded to the reaction temperature [13].

When increasing the IPA content of the reaction solution from 0 to $50 \mathrm{vol} \%$, both the light and heavy bio-oil products were found to increase steadily (Fig. 3a). However, the increase in the light oil phase (5.4 to $17.6 \mathrm{wt} \%$ ) was much more pronounced than that of the heavy biooil (8.0 to $10.7 \mathrm{wt} \%)$. At the same time, the solid yields remained almost constant (between 4.0 and $4.7 \mathrm{wt} \%$ ), whereas the water residue yields reduced significantly from 47.7 to $30.8 \mathrm{wt} \%$. Consequently, the overall product recovery remained relatively constant (ranging from $63 \mathrm{wt} \%$ at $50 \mathrm{vol} \%$ IPA to $70 \mathrm{wt} \%$ at $10 \mathrm{vol} \%$ IPA, with the unaccounted fraction likely to be gas product), suggesting that IPA helped to convert or transfer some of the water-soluble products into the bio-oil phase, without being incorporated into the bio-oil itself. This is contrary to previous liquefaction experiments using alcohols, where the product recoveries exceeded the initial amount of biomass added $[9,10]$. However, in these cases, the alcohols appeared to react
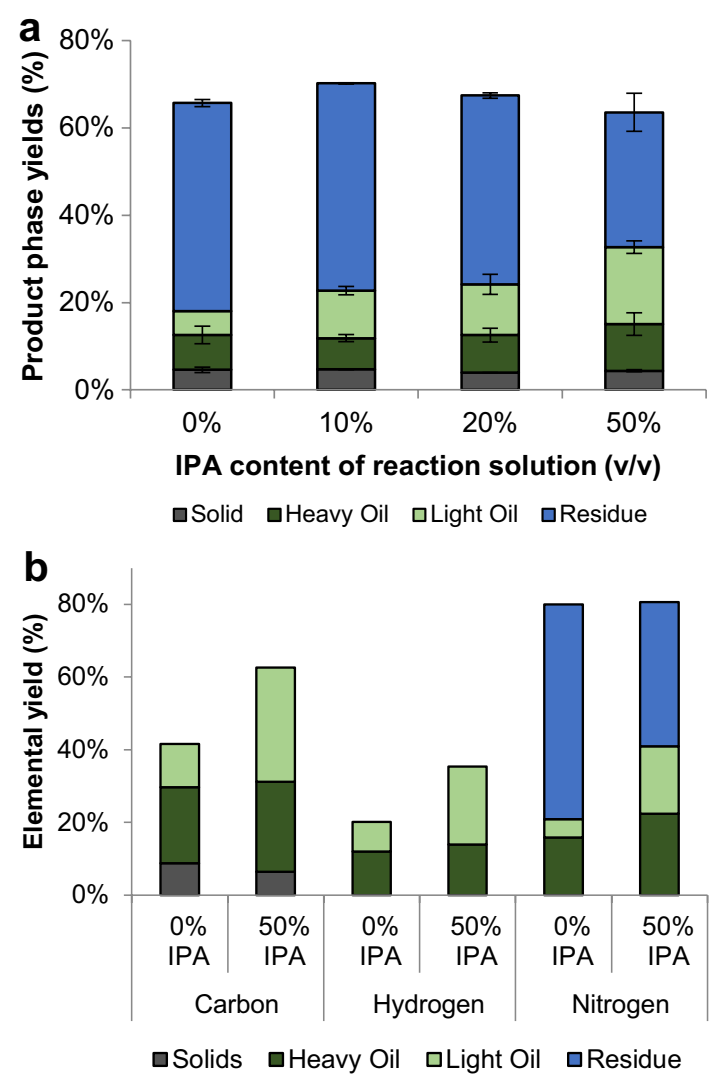

Fig. 3 Effect of IPA concentration in liquefaction medium for reactions at $310^{\circ} \mathrm{C}$ on a overall product distribution, of solids, heavy oil, light oil and the residue from the aqueous phase, $\mathbf{b}$ elemental distribution to different product phases

with the lipid fraction to form esters, whereas the algae press cake used in the present study contained only negligible amounts of residual lipids.

Compared to previous studies using ethanol-water solvent mixtures, commonly seen as the best solvent and which reported maximum oil yield increases of around $25 \%$ at optimized ethanol-water ratio, compared to the water-only reactions $[13,30]$, the increase in total oil yields obtained in the present study (111\%) is highly promising. However, it should be noted that due to the nature of the feedstock, the final yields of $28.3 \%$ are still significantly below the yields obtained in the cited studies (57.3 and $63 \%$ ), and therefore it is not possible to distinguish between the effect of the solvent (IPA vs. ethanol) or the differences in the feedstock.

Similar conclusions can be drawn from the elemental balance to the different product phases (Fig. 3b). Whilst the carbon retention in the solid remained relatively constant, the carbon, hydrogen and nitrogen distribution to the light oil phase increased significantly. The increase in bio-oil nitrogen content matched the reduction of nitrogen that partitioned into the aqueous phase, as calculated from the total 
nitrogen analysis of this phase, suggesting a direct transfer of nitrogen containing compounds from the aqueous to the bio-oil phase. (It should be noted that the presence of residual solvent in the water phase made it impossible to obtain meaningful results for the total carbon analysis of the water phase.)

When considering the ash content of the algae cake used for this study (53 wt \%), it is remarkable that the solid fraction amounted to only 4 to $5 \mathrm{wt} \%$ of the total reaction products. This confirms that a major portion of the ash consisted of highly water-soluble material (mostly sodium sulphate), which was recovered into the aqueous product phase instead. For the reaction in 50 vol\% IPA, the combined solid and water phase residue yields amounted to $35 \mathrm{wt} \%$, only just above the estimated sodium sulphate content in the biomass (33 wt\%), but significantly less than the total algae cake ash content. Consequently, a significant fraction of the ash appears to have been lost to the gas phase, or volatile water-soluble products, potentially through the thermal decomposition of carbonates into carbon dioxide, or the release of ammonia from ammonium salts.

Given the high ash content of the algal press cake, the bio-oil yields of $28.3 \mathrm{wt} \%$ obtained for an IPA loading of $50 \mathrm{vol} \%$ correspond to a high recovery of the organic fraction of $60.2 \mathrm{wt} \%$, significantly higher than the yields typically expected from the HTL of proteins (11-18\%) or carbohydrates (6-15\%) [7].

Despite these encouraging findings, it should be noted that the recovered algae cake accounted for only $43.6 \mathrm{wt} \%$ of the total carbon present in the lipid-extracted hydrolysate, and consequently the overall carbon recovery amounted to only $24.6 \%$. Attempts were made to recombine the algae cake with the 'neutral water' phase, recovered from the second centrifugation step, however the reaction resulted in the formation of hard solid deposits. These were presumably formed from the high loadings of sodium sulphate present in the neutral water phase, and would be expected to cause significant operational problems within an industrial setting. Consequently, the lipid extraction process needs to be improved to reduce, or eliminate, the amount of sulphuric acid required and facilitate the recovery of the lipid-extracted hydrolysate. Potential options are the use of higher hydrolysis temperatures, which would allow the use of lower acid concentrations, the use of solid acid catalysts, or the selection of algal strains with weaker cell walls, allowing the application of milder hydrolysis and lipid extraction conditions. Ideally, the entire lipidextracted hydrolysate would be processed directly, without further work-up, although the recovery of sugars and other nutrients may be desirable to allow their recycling for further algal growth.

Provided that these issues are addressed, it is expected that the combined lipid production and HTL of algae residues is significantly more favourable than algae lipid production on its own. Current estimates for lipid production costs from microalgae have been found to range widely [31], from around $\$ 1.9 \mathrm{~L}^{-1}$ for microalgae grown on wastewater [32] to $\$ 3.36 \mathrm{~L}^{-1}$ for an open pond, commercial size algal biofuel facility located in Southwest USA [33], significantly above currently acceptable fuel costs. Similarly, estimates of the environmental burden and energy returns on investment have given widely disparate results, due to different modelling assumptions [34]. Yuan et al. estimated a minimum lifecycle energy requirement of $2.35 \mathrm{MJ}$ for each $\mathrm{MJ}$ of algal biodiesel and green house gas emissions of $143 \mathrm{~g}\left(\mathrm{CO}_{2}\right) \mathrm{MJ}^{-1}$, although these figures were reduced to $1.02 \mathrm{MJ} \mathrm{MJ}^{-1}$ and $71 \mathrm{~g}\left(\mathrm{CO}_{2}\right) \mathrm{MJ}^{-1}$ when applying anaerobic digestion (AD) to the lipid-extracted residue [35]. Only slightly better results were obtained by Clarens et al., who calculated energy returns of investment ranging from 0.65 to 1.13 for a biodiesel production process, combined with $\mathrm{AD}$, depending on the source of carbon and other nutrients [36]. In contrast, Stephenson et al. estimated a fossil-energy requirement reduction of $85 \%$ and global warming potential reduction of $78 \%$ compared to fossilderived diesel [37]. In all these studies, the major contributors to the overall lifecycle burden are the algae cultivation and pretreatment steps, and therefore further energy recovery of the lipid-extracted algal residue is highly beneficial. Algal biofuel production via HTL appears more beneficial as demonstrated by a previous life-cycle analysis giving an energy-return-on-investment of a full-scale process comparable to fossil-derived diesel and gasoline, whilst the greenhouse gas emissions were reduced to less than a third [34].

\section{HTL in the Presence of Steel Furnace Residues}

In an attempt to increase the bio-oil yields from the liquefaction of the algae cake, and potentially lower the reaction temperatures, the reaction was conducted in the presence of two steel furnace residues, ladle-furnace residue (LFR) and electric-arc furnace slag (EAFS). LFR consisted predominantly of calcium and silicon oxides, with smaller quantities of carbon, magnesium and titanium. EAFS also contained significant amounts of calcium and silicon oxides, magnesium and carbon, but also contained significant fractions of iron, aluminium, manganese and titanium. Consequently, both materials could potentially enhance basecatalysed reactions, whereas EAFS could also be active for iron-catalysed cross-coupling or hydrogenation reactions.

It should be noted that the objective of the present study was to evaluate the overall catalytic activity of these materials for the conversion of the lipid-extracted algae cake as well as testing their stability under HTL conditions. Both materials are waste products, and therefore available at low cost, although industrial processing may be limited by 
the additional energy requirements of heating these materials to reaction temperature and suspending them within the reaction stream. A potential way of addressing these limitations would be to conduct the HTL reaction in two stages, by combining a continuous stirred tank reactor (CSTR) with a plug flow reactor, similar to the configuration employed by Elliott et al. [38]. The catalyst could then be retained within the CSTR, whilst the reaction continues within the secondary plug flow reactor.

As in the previous section, reactions were conducted at $310^{\circ} \mathrm{C}$, in pure water and $50 \mathrm{vol} \%$ IPA, however, additional reactions were carried out at $220^{\circ} \mathrm{C}$. As this temperature is below the critical temperature of pure IPA $\left(235.1{ }^{\circ} \mathrm{C}\right)$, the reactions were also conducted in pure IPA, as well as in 50 vol $\%$ IPA and in pure water.

\section{Catalyst Stability}

An important consideration for using catalysts is the ease with which they can be recovered and recycled after the reaction. Consequently, heterogeneous catalysts are generally preferred over homogeneous catalysts, however they must be stable during the reaction conditions to prevent the loss of catalytic material into the product phases, resulting in potential contamination issues. To assess the suitability of the two steel furnace residues for the HTL of algae press cake, the study tracked the recovery of the major elemental components in the solid phase.

LFR Apart from oxygen and carbon, which were not tracked as they are also present in the biomass itself, LFR contained significant quantities of calcium (34.6 wt\%), silicon (11.1 wt \%) and magnesium (1.5 wt\%), shown in Table 2.

During the reaction at $220^{\circ} \mathrm{C}$ in pure water, substantial amounts of silicon and magnesium were lost, whereas calcium retention was close to $80 \%$ (See supporting information). Following the introduction of IPA to the reaction medium, the silicon and magnesium recovery increased significantly, with the calcium recovery appearing to drop slightly. The reverse trend was observed at $310^{\circ} \mathrm{C}$. At this temperature the recovery of silicon and magnesium in pure water was significantly enhanced, compared to the reaction at $220^{\circ} \mathrm{C}$, but dropped for the reaction conducted in the presence of IPA.
The data suggests that under HTL conditions, all three elements display high solubility in the water phase. Calcium oxide is known to react with water to form calcium hydroxide, whereas the solubility of magnesium oxides in water increases with increasing temperature. Amorphous silicon dioxide in turn was previously found to display a maximum water solubility of $1660 \mathrm{mg} \mathrm{kg}^{-1}$ at a temperature of $340^{\circ} \mathrm{C}$ [39]. A potential explanation for the enhanced retention of calcium, compared to silicon and magnesium, is its higher concentration within LFR, resulting in full saturation of the water phase. Consequently, the recovery of silicon and magnesium increased following the introduction of IPA, as the volume of water decreased. However, it is clear that this correlation broke down at the higher reaction temperature of $310^{\circ} \mathrm{C}$ and suggests that the catalyst underwent chemical changes to modify its solubility in the reaction medium. Calcium could have reacted with the sulphates in the press cake to form gypsum, whereas silicon and magnesium could have been reduced or adapted more stable configurations. The overall water loading and the presence of IPA would have been expected to influence the equilibrium between these reactions, ultimately affecting the final product phase distribution.

In all cases, it should be noted that the data contains a large degree of uncertainty. Apart from the general limitations of using SEM-EDX, this may be related to a nonuniform composition of the solid reaction product as well as the difficulty of fully recovering solid precipitates from the reactor walls.

EAFS Compared to LFR, EAFS contained less calcium (12.1 wt \%) and silicon (6.7 wt\%), but a higher amount of magnesium (2.3 wt\%). It also contained significant quantities of iron (12.6 wt\%), aluminium (1.9 wt\%), manganese (1.4 wt \%) and titanium ( $0.3 \mathrm{wt} \%)$, and consequently the recovery of all seven elements was tracked following the HTL reaction (Table 2).

Despite its low concentration, within error, titanium appeared to have been fully recovered into the solid phase at all reaction conditions (see supporting information). The recovery of magnesium and silicon appeared to be increased, compared to LFR, whereas the calcium recovery remained about the same. Iron recovery at $220^{\circ} \mathrm{C} \mathrm{did}$ not follow a clear trend, reaching around $100 \%$ for an IPA

Table 2 Elemental composition from SEM-EDX analysis of materials tested as HTL catalysts; (a) Ladle-furnace residue (LFR), (b) Electric-arc furnace slag (EAFS)

\begin{tabular}{lllllllllll}
\hline & $\mathrm{C}$ & $\mathrm{O}$ & $\mathrm{Mg}$ & $\mathrm{Al}$ & $\mathrm{Si}$ & $\mathrm{Ca}$ & $\mathrm{Ti}$ & $\mathrm{Mn}$ & $\mathrm{Fe}$ & $\mathrm{Other}$ \\
\hline Furnace residue & 13.8 & 44.9 & 2.3 & 1.9 & 6.7 & 12.1 & 0.3 & 1.4 & 12.6 & 4.0 \\
Furnace flour & 7.0 & 42.4 & 1.5 & $\mathrm{nd}$ & 11.1 & 34.6 & 0.2 & nd & nd & 3.2 \\
\hline
\end{tabular}

nd - not detected 
concentration of $50 \mathrm{vol} \%$, but recoveries of only $55 \%$ in pure water and $42 \%$ in pure IPA. The manganese recovery followed a similar trend to iron, remaining around $60 \%$ at all conditions, apart for the 50 vol $\%$ IPA loading at $220^{\circ} \mathrm{C}$, whereas the aluminium recovery remained consistently above $80 \%$. The low recovery of iron and manganese for the reaction in pure IPA is surprising, as only three product phases (solid, oil and gas) were collected from the reactor. A potential explanation could be the formation of iron and manganese deposits on the reactor walls, which were difficult to recover after the reaction.

Consistent with the results for LFR, the calculated elemental recoveries showed a high degree of experimental uncertainty. Whilst EAFS appeared to display a higher overall stability than LFR, the reaction still caused a significant portion of magnesium, silicon, iron and manganese to partition into the water phase. Particularly the dissolution of manganese to the water phase could be problematic, due to its known neurotoxicity at elevated groundwater concentrations [40].

\section{Product Distribution}

Compared to the water-only reactions, at $220^{\circ} \mathrm{C}$, the addition of $50 \mathrm{vol} \%$ IPA to the reaction medium resulted in a significant increase in the bio-oil yields obtained from both the catalytic and the blank reactions (Fig. 4a). Solid yields remained relatively constant, whereas the water phase residue yields experienced a significant drop, together with a reduction in the overall mass balance closure, indicating enhanced gas formation.

Conducting the reactions in pure IPA resulted in only a small further increase in bio-oil yields, compared to the reactions in 50 vol\% IPA. No water phase was present for these reactions, and consequently no water phase residue was recovered. In contrast, the solid yields increased significantly from less than $20 \mathrm{wt} \%$ at an IPA loading of $50 \mathrm{vol} \%$ to up to $45.7 \mathrm{wt} \%$ for the reaction catalysed with LFR. This large increase can be attributed to the high quantity of water-soluble ash present in the algae cake. For reactions conducted in water, these salts were dissolved and subsequently removed together with the aqueous phase (and precipitated as water phase residue), but in the absence of water, the salts remained part of the solid product fraction. Even so, the maximum solid recovery of $45.7 \mathrm{wt} \%$ remained below the total ash content of the algae cake (52.9 wt\%), suggesting that during the reaction, some of the inorganic press cake components were either dissolved into the IPA phase, or decomposed into gas phase products.

For the reactions at $220^{\circ} \mathrm{C}$, the presence of LFR and EAFS did not appear to have a positive effect on the product distributions obtained from the HTL of the algae cake. In pure water, the overall bio-oil yields were significantly lower for the reactions involving the two catalysts $(6.0 \mathrm{wt} \%$ for LFR and $5.7 \mathrm{wt} \%$ for EAFS), compared to a yield of $8.4 \mathrm{wt} \%$ for the non-catalytic reaction. Following the introduction of IPA, the difference became less pronounced, but maximum overall oil yields of $14.5 \mathrm{wt} \%$ at an IPA loading of $50 \mathrm{vol} \%$ and $18.8 \mathrm{wt} \%$ in pure IPA were still obtained for the non-catalytic reactions. However, compared to the blank run, EAFS did appear to slightly favour the formation of light, hexane-soluble oil.

The solid yields obtained in the presence of EAFS were comparable to the non-catalytic reaction at all three IPA loadings, whereas the yields obtained with LFR were significantly enhanced for the reactions conducted in the presence of IPA. Even though the solid yield enhancement appeared to be less significant in pure water, it should be noted that at this condition, a significant amount of catalyst

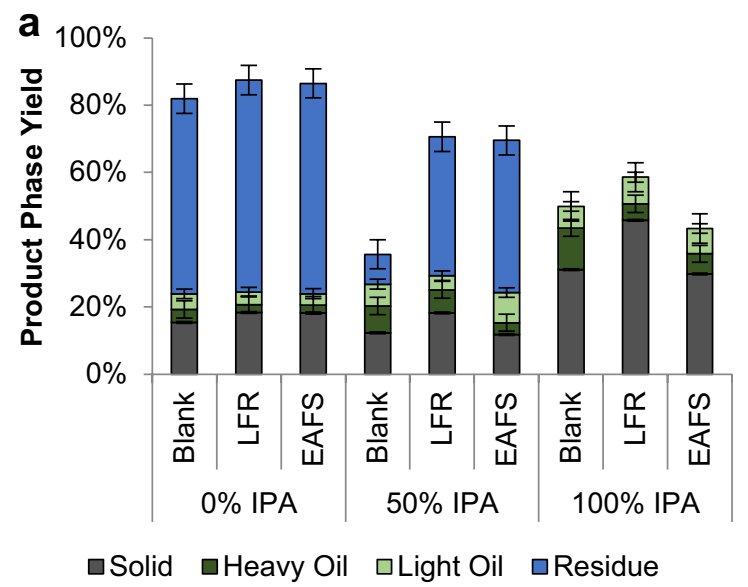

b

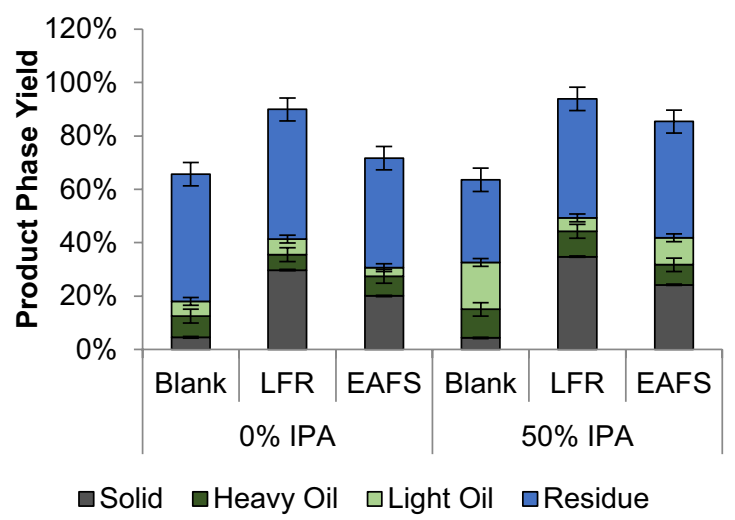

Fig. 4 Effect of adding LRF and EAFS to the reaction during the liquefaction of algae cake in the presence of varying concentrations of IPA; a reaction at $220^{\circ} \mathrm{C}, \mathbf{b}$ reaction at $310^{\circ} \mathrm{C}$ 
was lost to the water phase, potentially counter-acting the effect of increased solid formation.

At $310^{\circ} \mathrm{C}$ the difference between the blank and catalytic runs was much more noticeable than at $220^{\circ} \mathrm{C}$ (Fig. 4b). Both catalysts resulted in a significant reduction in bio-oil yields, and a large increase in solid yields, particularly in the presence of $50 \mathrm{vol} \%$ IPA. All water residue yields in pure water were approximately equal, but for the non-catalytic runs, the yields reduced significantly from $47.7 \mathrm{wt} \%$ to $30.8 \mathrm{wt} \%$ following the addition of $50 \mathrm{vol} \%$ IPA, whereas they remained unchanged around $41 \mathrm{wt} \%$ to $49 \mathrm{wt} \%$ for the catalytic reactions. This suggests that the presence of IPA helped to transfer organics from the water-phase into the bio-oil, whereas the catalysts increased the formation of solids, potentially through enhanced coke or char formation on the catalyst surface. This is consistent with previous work that has shown that the presence of inorganic salts, including potassium carbonate and calcium acetate, can enhance secondary char formation during the pyrolysis of lignocellulosic biomass [41, 42]. The presence of these metals appeared to reduce the pyrolysis temperature of the biomass, as well as influencing the relative rates of polymerization and cracking reactions of intermediate decomposition products to favour either char or gas formation [43]. Whilst pyrolysis reactions are mostly limited to the solid and gas phase, secondary HTL reactions proceed within the aqueous phase. Consequently, higher salt concentrations may be required to have a similar effect, resulting in higher char yields in the presence of calcium-rich LFR, compared to the more stable EAFS.

Comparing the results obtained for the non-catalytic reactions shows that the overall bio-oil yields obtained at $220^{\circ} \mathrm{C}$ in the presence of $50 \mathrm{vol} \%$ IPA $(14.5 \mathrm{wt} \%)$ and pure IPA $(18.8 \mathrm{wt} \%)$ were higher than the bio-oil yields obtained at $310^{\circ} \mathrm{C}$ and in pure water $(13.4 \mathrm{wt} \%)$. The same trends were observed for the bio-oil yields obtained from the catalytic reactions, however it should be noted that the reactions at $310^{\circ} \mathrm{C}$, in $50 \mathrm{vol} \%$ IPA, always yielded the highest oil yields of all conditions studied. Solid yields, in turn, were lower for both non-catalytic reactions at $310^{\circ} \mathrm{C}$, than for any of the reactions at $220^{\circ} \mathrm{C}$, but the opposite trend was observed for the reactions involving LFR and EAFS.

\section{Elemental Recovery}

To study the effect of reaction temperature, IPA content and the presence of the catalysts in more detail, the distribution of carbon, hydrogen and nitrogen to the oil and solid phases was calculated for the reactions in pure IPA at $220^{\circ} \mathrm{C}$ and the two reaction conditions at $310^{\circ} \mathrm{C}$, in pure water and with a 50 vol\% IPA loading (Fig. 5).

Consistent with the higher oil yields obtained at $220^{\circ} \mathrm{C}$ in pure IPA, compared to the reaction at $310^{\circ} \mathrm{C}$ in pure
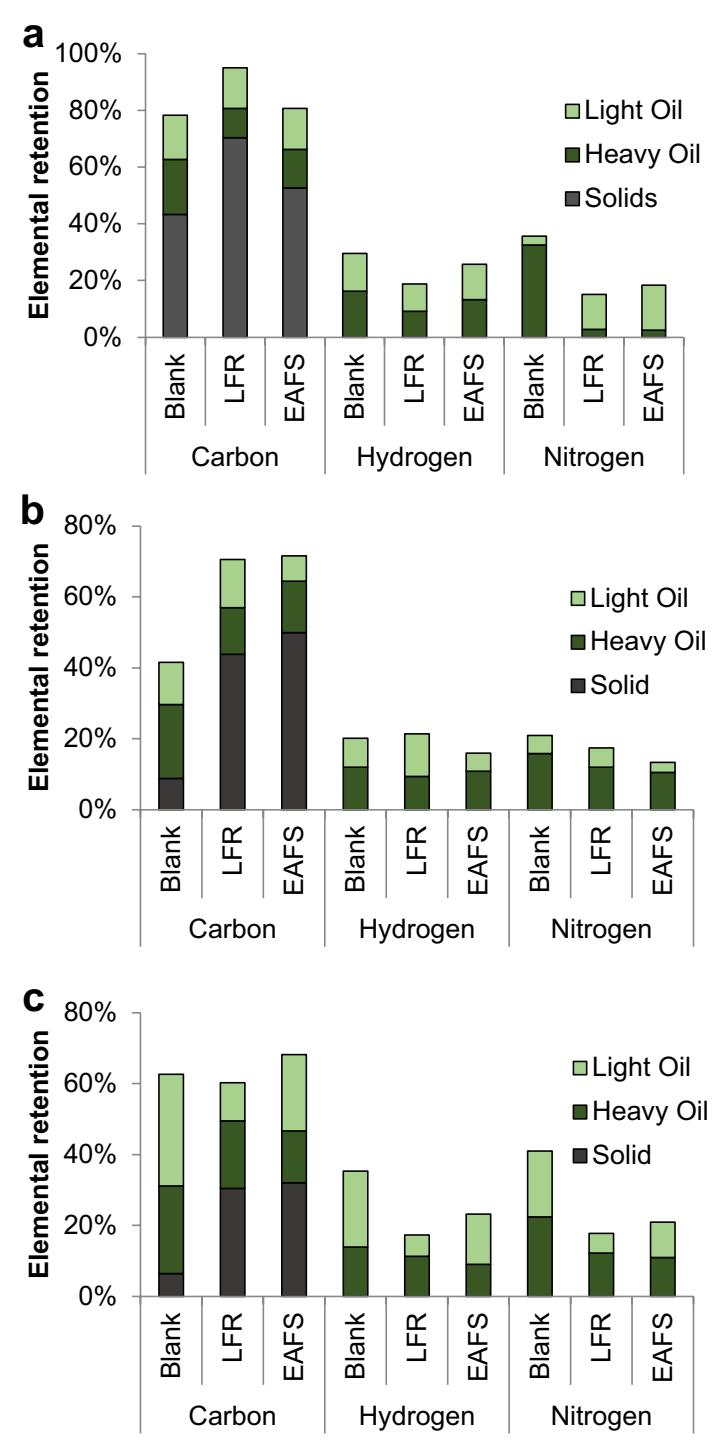

Fig. 5 Effect of catalyst on elemental distribution to the bio-oil phase; a $220^{\circ} \mathrm{C}, 100$ vol\% IPA, b $310^{\circ} \mathrm{C}, 0$ vol\% IPA, c $310^{\circ} \mathrm{C}$, 50 vol $\%$ IPA

water, the carbon and hydrogen recoveries to the oil phase for the non-catalytic reactions were slightly increased from 32.8 to $34.9 \%$ and $20.2 \%$ to $29.5 \%$, respectively. At the same time, the nitrogen recovery was significantly elevated from 21.0 to $35.6 \%$, resulting in an overall increase in the nitrogen content of the bio-oil from 4.7 to $6.6 \mathrm{wt} \%$. Similarly, the contribution of the unaccounted elemental fraction (predominantly oxygen) to the overall oil yield increased from 13.5 to $18.8 \mathrm{wt} \%$.

The addition of 50 vol\% IPA to the reaction medium at $310^{\circ} \mathrm{C}$ resulted in a large increase in the total carbon and hydrogen recovery to the bio-oil, and was comparable to the simultaneous increase in nitrogen recovery, resulting in similar overall nitrogen contents in the oil of $4.7 \mathrm{wt} \%$ for the reaction in pure water and $4.8 \%$ in the presence of IPA. 
Despite this, the increased retention of carbon, hydrogen and nitrogen could not account for the entire increase in oil yields, resulting in an increase in the unaccounted elemental fraction from 13.5 to $19.0 \mathrm{wt} \%$. The $\mathrm{H} / \mathrm{C}$ mass ratio only increased marginally from 0.118 to 0.121 , suggesting limited transfer of hydrogen from IPA to the bio-oil. This is not surprising, as this reaction generally requires a good hydrogenation catalyst, such as RANEY® Nickel. Carbon recoveries to the solid phase were significantly higher at the lower reaction temperature $(43.3 \%)$ than at $310^{\circ} \mathrm{C}(8.8 \%$ in pure water and $6.4 \%$ in $50 \mathrm{vol} \%$ IPA), consistent with the differences in solid yields and the absence of a water phase residue for the reaction in pure IPA.

Slightly different trends were obtained for the reactions over the two catalysts. Whilst the highest carbon and nitrogen recoveries were still obtained at $310^{\circ} \mathrm{C}$ and in the presence of IPA, the hydrogen recovery was reduced compared to the reaction at $220^{\circ} \mathrm{C}$, and the nitrogen content in the bio-oil was higher for the reaction in pure water. The carbon recovery to the solid phase at $310^{\circ} \mathrm{C}$ was also decreased in the presence of $50 \mathrm{vol} \%$ IPA, contrary to the simultaneous increase in solid yields. This suggests that the increase in solid yield can be mostly attributed to reduced dissolution of inorganic material from the algae cake and the catalysts, whilst IPA helped the recovery of organic carbon into the bio-oil.

These findings show that the addition of IPA to the liquefaction medium can result in a significant enhancement of liquefaction yields, potentially allowing the reaction to proceed under much milder conditions compared to the pure water-phase reaction. However, the bio-oil quality obtained at $220^{\circ} \mathrm{C}$ was also reduced, as indicated by an increased oxygen and nitrogen content. This was probably the result of incorporating lighter, water-soluble organics into the bio-oil, which contained high concentrations of oxygen and nitrogen. Furthermore, the reaction in pure IPA is unlikely to be feasible for industrial scale production, as it requires highly energy-intensive drying steps to obtain the fully dried biomass. In contrast, liquefaction in the presence of $50 \mathrm{vol} \%$ IPA at $310^{\circ} \mathrm{C}$ offered a good compromise between enhanced oil yields and reduced biomass drying. Whilst it caused a reduction in the carbon and hydrogen content in the bio-oil, due to the increased incorporation of oxygen, it only had a limited impact on the nitrogen content from the non-catalytic reaction, and even reduced the nitrogen content for reaction with the two furnace residue materials.

Neither of the two catalysts employed for this study resulted in an increase in bio-oil yields. LFR in particular caused an increase in solid yields and decreased the biooil yields without having any obvious beneficial impact on bio-oil composition. It was previously hoped that the basic nature of the catalysts would help the conversion of carbohydrates into bio-oil products. However, it is possible that the high ash content of the microalgae cake itself (53 wt $\%$ ) provided sufficient quantities of base catalyst, and therefore the presence of LFR had no further beneficial impact. EAFS also reduced bio-oil yields and increased solid content, but had a beneficial impact on the carbon and hydrogen contents of the bio-oils obtained by the reaction, related to a reduced oxygen concentration. This suggests that the iron catalysed the deoxygenation reaction, however as iron only accounted for a small fraction of the overall catalyst material (12.6 wt \%), the beneficial impact was outweighed by the reduction in bio-oil yields.

\section{Conclusions}

Combining algal lipid production with HTL is a promising method for realising the benefits of both methods, of producing higher value fuels at lower overall production costs. Both the production of lipid heterotrophically and the hydrothermal liquefaction of algae have been demonstrated on the pilot scale separately previously, however, the two processes would need to carefully integrated, to prevent contamination of the algae residue during the lipid extraction stage, and optimize the lipid-content of the algae to achieve the best compromise between product yields and cultivation costs.

Conducting the HTL of lipid-extracted algae in the presence of $50 \mathrm{vol} \%$ IPA resulted in remarkably high recoveries of the organic fraction to the bio-oil phase of up to $60.2 \mathrm{wt} \%$, significantly above the oil yields typically expected from carbohydrates or proteins. It also allowed the application of much lower reaction temperatures, to obtain comparable oil yields to a water-only reaction, albeit with a significant reduction in bio-oil quality, as a result of increased nitrogen and oxygen incorporation. However, this approach proved only feasible if the water-phase was extracted with a non-polar solvent, to allow the recovery of IPA and light organic products. Therefore, further studies including cost-benefit analyses are required to assess the feasibility of the overall process.

The addition of two steel furnace residues, LFR and EAFS, as potential liquefaction catalysts, appeared to have no beneficial impact on bio-oil yields, but instead resulted in a significant increase in solid yields, potentially due to the formation of char and coke over the catalyst surface. At the same time, the liquefaction reaction resulted in significant leaching of calcium, silicon, magnesium, iron and manganese to the water phase. In particular, the loss of manganese could be a major problem due to its known neurotoxic effect. Nevertheless, the presence of EAFS had a positive effect on the carbon, hydrogen and nitrogen contents of the bio-oils produced in 50 vol\% IPA, suggesting 
that it could have a low activity towards deoxygenation and denitrogenation reactions, most likely catalysed by its iron content of $12.6 \mathrm{wt} \%$. Future work could therefore explore the use of more stable, iron-based catalysts, to obtain more favourable bio-oil compositions.

Acknowledgements The authors would like to ackonwledge Prof. Ulf Schuchardt for all his input and guidance at the start of the project. This work was funded by the Engineering and Physical Sciences Research Council (EP/G03768X/1) and the University of Bath Global Research Scholarship Scheme. The data repository can be freely accessed at (10.15125/BATH-00353).

Open Access This article is distributed under the terms of the Creative Commons Attribution 4.0 International License (http:// creativecommons.org/licenses/by/4.0/), which permits unrestricted use, distribution, and reproduction in any medium, provided you give appropriate credit to the original author(s) and the source, provide a link to the Creative Commons license, and indicate if changes were made.

\section{References}

1. Chisti, Y.: Constraints to commercialization of algal fuels. J. Biotechnol. 167, 201-214 (2013)

2. Rodolfi, L., Chini Zittelli, G., Bassi, N., Padovani, G., Biondi, N., Bonini, G., Tredici, M. R.: Microalgae for oil: strain selection, induction of lipid synthesis and outdoor mass cultivation in a low-cost photobioreactor. Biotechnol. Bioeng. 102(1), 100-112 (2009)

3. Kalnes, T.N., Marker, T., Shonnard, D.R., Koers, K.P.: Green diesel production by hydrorefining renewable feedstocks. In Biofuels Technology, pp 7-11 (2008)

4. Mikkonen, S., Hartikka, T., Kuronen, M., Saikkonen, P: HVO, Hydrotreated Vegetable Oil-a Premium Renewable Biofuel for Diesel Engines, Neste Oil Corporation: 2012.

5. López Barreiro, D., Prins, W., Ronsse, F., Brilman, W.: Hydrothermal liquefaction (HTL) of microalgae for biofuel production: State of the art review and future prospects. Biomass Bioenergy. 53, 113-127 (2013)

6. Tian, C., Li, B., Liu, Z., Zhang, Y., Lu, H.: Hydrothermal liquefaction for algal biorefinery: A critical review. Renew. Sus. Energ. Rev. 38, 933-950 (2014)

7. Biller, P., Ross, A.B.: Potential yields and properties of oil from the hydrothermal liquefaction of microalgae with different biochemical content. Bioresour. Technol. 102(1), 215-225 (2011)

8. Wagner, J., Bransgrove, R., Beacham, T. A., Allen, M. J., Meixner, K., Drosg, B., Ting, V. P., Chuck, C.J.: Co-production of bio-oil and propylene through the hydrothermal liquefaction of polyhydroxybutyrate producing cyanobacteria. Bioresour. Technol. 207, 166-174 (2016)

9. Duan, P., Jin, B., Xu, Y., Yang, Y., Bai, X., Wang, F., Zhang, L., Miao, J.: Thermo-chemical conversion of Chlorella pyrenoidosa to liquid biofuels. Bioresour. Technol. 133, 197-205 (2013)

10. Jin, B., Duan, P., Zhang, C., Xu, Y., Zhang, L., Wang, F.: Noncatalytic liquefaction of microalgae in sub-and supercritical acetone. Chem. Eng. J. 254, 384-392 (2014)

11. Huang, H.-j., Yuan, X.-Z., Zhu, H.-n., Li, H., Liu, Y., Wang, X.-1., Zeng, G.-m.: Comparative studies of thermochemical liquefaction characteristics of microalgae, lignocellulosic biomass and sewage sludge. Energy. 56, 52-60 (2013)
12. Lu, J., Liu, Z., Zhang, Y., Li, B., Lu, Q., Ma, Y., Shen, R., Zhu, Z.: Improved production and quality of biocrude oil from lowlipid high ash macroalgae Enteromorpha prolifera via addition of crude glycerol. J. Clean. Prod. 142, 749-757 (2017).

13. Chen, Y., Wu, Y., Zhang, P., Hua, D., Yang, M., Li, C., Chen, Z., Liu, J.: Direct liquefaction of Dunaliella tertiolecta for biooil in sub/supercritical ethanol-water. Bioresour. Technol. 124, 190-198 (2012)

14. Jade, C., Pattarapan, P.: Bio-oil from hydro-liquefaction of bagasse in supercritical ethanol. Energy Fuel. 24, 2071-2077 (2010)

15. Caporgno, M. P., Pruvost, J., Legrand, J., Lepine, O., Tazerout, M., Bengoa, C.: Hydrothermal liquefaction of Nannochloropsis oceanica in different solvents. Bioresour. Technol. 214, 404-410 (2016)

16. Wang, X, Rinaldi R: Exploiting H-transfer reactions with RANEY® Ni for upgrade of phenolic and aromatic biorefinery feeds under unusual, low-severity conditions. Energ. Env. Sci. 5, 8244 (2012).

17. Wang, X., Rinaldi R.: A route for lignin and bio-oil conversion: dehydroxylation of phenols into arenes by catalytic tandem reactions. Angew. Chem. Int. Ed. Engl. 52, 11499-11503 (2013)

18. Han, J. X., Duan, J. Z., Chen, P., Lou, H., Zheng, X. M., Hong, H. P.: Nanostructured molybdenum carbides supported on carbon nanotubes as efficient catalysts for one-step hydrodeoxygenation and isomerization of vegetable oils. Green Chem. 13, 2561-2568 (2011)

19. Yang, L., Li, Y., Savage, P.E.: Catalytic Hydrothermal Liquefaction of a Microalga in a Two-Chamber Reactor. Ind. Eng. Chem. Res. 53(30), 11939-11944 (2014)

20. Raikova, S., Smith-Baedorf, H., Bransgrove, R., Barlow, O., Santomauro, F., Wagner, J. L., Allen, M. J., Bryan, C. G., Sapsford, D., Chuck, C. J.: Assessing hydrothermal liquefaction for the production of bio-oil and enhanced metal recovery from microalgae cultivated on acid mine drainage. Fuel Process. Technol. 142, 219-227 (2016)

21. Rojas-Pérez, A., Diaz-Diestra, D., Frias-Flores, C. B., BeltranHuarac, J., Das, K., Weiner, B. R., Morell, G., Díaz-Vázquez, L. M.: Catalytic effect of ultrananocrystalline $\mathrm{Fe}_{3} \mathrm{O}_{4}$ on algal biocrude production via HTL process. Nanoscale, 7(42), 17664 17671 (2015)

22. Li, P., Yu, Q., Qin, Q., Lei, W.: Kinetics of CO2/Coal Gasification in Molten Blast Furnace Slag. Ind. Eng. Chem. Res. 51(49), 15872-15883 (2012)

23. Kar, Y., Gürbüz, Z.: Application of blast furnace slag as a catalyst for catalytic cracking of used frying sunflower oil. Energ. Explor. Exploit. 34(2), 262-272 (2016)

24. Luo, S., Zhou, Y., Yi, C.: Hydrogen-rich gas production from biomass catalytic gasification using hot blast furnace slag as heat carrier and catalyst in moving-bed reactor. Int. J. Hydrogen Energ. 37(20), 15081-15085 (2012)

25. Nasuha, N., Ismail, S., Hameed, B. H.: Activated electric arc furnace slag as an efficient and reusable heterogeneous Fenton-like catalyst for the degradation of Reactive Black 5. J. Taiwan Inst. Chem. Eng. 67, 235-243 (2016)

26. Coelho, R.S., Vidotti, A.D.S., Reis, É.M., Franco, T.T.: High Cell Density Culture of Microalgae under Fed-batch and Continuous Growth. Chem. Eng. Transa. 38, 313-318 (2014)

27. Mubarak, M., Shaija, A., Suchithra, T.: A review on the extraction of lipid from microalgae for biodiesel production. Algal Res. 7, 117-123 (2015).

28. López Barreiro, D., Riede, S., Hornung, U., Kruse, A., Prins, W.: Hydrothermal liquefaction of microalgae: effect on the product yields of the addition of an organic solvent to separate the aqueous phase and the biocrude oil. Algal Res. 12, 206-212 (2015) 
29. Valdez, P. J., Dickinson, J. G. Savage, P.E.: Characterization of Product Fractions from Hydrothermal Liquefaction of Nannochloropsis sp: and the Influence of Solvents. Energ. Fuels. 25(7), 3235-3243 (2011)

30. Zhang, J., Zhang, Y.: Hydrothermal liquefaction of microalgae in an ethanol-water co-solvent to produce biocrude oil. Energ. Fuel. 28(8), 5178-5183 (2014)

31. Davis, R., Aden, A., Pienkos, P.T., Techno-economic analysis of autotrophic microalgae for fuel production. App. Energ. 88(10), 3524-3531 (2011)

32. Lundquist, T., Woertz, I., Quinn, N., Benemann, J.: A Realistic Technology and Engineering Assessment of Algae Biofuel Production. Energy Biosciences Institute, University of California, Berkeley (2010)

33. Richardson, J.W., Johnson, M.D., Outlaw, J.L., Economic comparison of open pond raceways to photo bio-reactors for profitable production of algae for transportation fuels in the Southwest. Algal Res. 1(1), 93-100 (2012)

34. Liu, X., Saydah, B., Eranki, P., Colosi, L. M., Greg Mitchell, B., Rhodes, J., Clarens, A.F.: Pilot-scale data provide enhanced estimates of the life cycle energy and emissions profile of algae biofuels produced via hydrothermal liquefaction. Bioresour. technol. 148, 163-171 (2013)

35. Yuan, J., Kendall, A., Zhang, Y., Mass balance and life cycle assessment of biodiesel from microalgae incorporated with nutrient recycling options and technology uncertainties. GCB Bioenerg. 7(6), 1245-1259 (2015)

36. Clarens, A.F., Nassau, H., Resurreccion, E. P., White, M.A., Colosi, L.M.: Environmental impacts of algae-derived biodiesel and bioelectricity for transportation. Environ. Sci. Technol. 45(17), 7554-7560 (2011)

37. Stephenson, A. L., Kazamia, E., Dennis, J. S., Howe, C.J., Scott, S.A., Smith, A.G.: Life-cycle assessment of potential algal biodiesel production in the United Kingdom: a comparison of raceways and air-lift tubular bioreactors. Energ. Fuels. 24(7), 40624077 (2011)

38. Elliott, D.C., Hart, T.R., Schmidt, A.J., Neuenschwander, G.G., Rotness, L.J., Olarte, M.V., Zacher, A.H., Albrecht, K.O., Hallen, R.T., Holladay, J.E.: Process development for hydrothermal liquefaction of algae feedstocks in a continuous-flow reactor. Algal Res. 2(4), 445-454 (2013)

39. Fournier, R.O., Rowe, J.J.: The solubility of amorphous silica in water at high temperatures and high pressures. Am. Mineral. 62, 1052-1056 (1977)

40. Bouchard, M.F., Sauve, S., Barbeau, B., Legrand, M., Brodeur, M.E., Bouffard, T., Limoges, E., Bellinger, D.C., Mergler, D.: Intellectual impairment in school-age children exposed to manganese from drinking water. Environ. Health Perspect. 119(1), 138-143 (2011)

41. DeGroot, W.F., Shafizadeh, F.: Effect of inorganic species on char formation from biomass fuels. Preprints of Papers - American Chemical Society, Division of Fuel. Chemistry. 29(2), 146153 (1984)

42. Williams, P.T., Horne, P.A.: The role of metal salts in the pyrolysis of biomass. Renew. Energ. 4(1), 1-13 (1994)

43. Zaror, C.A., Hutchings, I.S., Pyle, D.L., Stiles, H.N., Kandiyoti, R.: Secondary char formation in the catalytic pyrolysis of biomass. Fuel. 64(7), 990-994 (1985) 